\title{
Transtorno de personalidade borderline em homens: uma revisão integrativa
}

\author{
Borderline personality disorder in men: \\ an integrative review
}

\section{Rodrigo Barbosa Nascimento' ${ }^{1}$ \\ Gabriela de Lima Cerqueira2 (1) Emanuel Santos de Araujo Filho 3 (1) Daniela Gomes Carneiro ${ }^{4}$ (1)}

\author{
${ }^{1}$ Autor para correspondência. Universidade Salvador (Feira de Santana). Bahia, Brasil. nascimentolag@gmail.com \\ 2-4Universidade Salvador (Feira de Santana). Bahia, Brasil. gabriela27cerqueira@gmail.com, emanuelfilho616@gmail.com, dangoes.1943@gmail.com
}

RESUMO I OBJETIVO: Apresentar e sistematizar as principais evidências científicas a respeito do transtorno de personalidade borderline em homens (TPB). MÉTODO: Durante o período de abril de 2021, realizou-se uma revisão integrativa da literatura científica acerca da temática em questão, sendo utilizados os descritores indexados no DeCS: Transtorno da Personalidade Borderline; Transtorno da Personalidade Limítrofe; Masculino; Fatores Desencadeantes; Cognição; Neurobiologia; Comportamento Social. Para realizar a pesquisa, os descritores foram combinados nas bases de dados Medline, Lilacs e EBCS nos sites de Busca Pubmed e na Biblioteca Virtual em Saúde - BVS. RESULTADOS: Foi possível identificar algumas alterações comportamentais, de humor e neuropsicológicas em homens com TPB. Dentre as alterações comportamentais, a mais prevalente foi a agressão (37,5\% dos artigos). Do mesmo modo, a alteração de humor mais encontrada foi a desregulação emocional ( $12,5 \%$ dos artigos), muito comum em pacientes com TPB; igualmente, as alterações a nível neuropsicológico com maior quantidade de achados envolvem alteraç̃̃es na região da amígdala (20,83\% dos artigos), córtex ( $16,66 \%$ dos artigos), bem como o hipocampo (16,66\% dos artigos), regiões essenciais para o controle do humor e tomada de decisão. CONCLUSÃo: Foi possível concluir que existem algumas alterações comportamentais, de humor e neuropsicológicas que são mais prevalentes no gênero masculino, sobretudo aquelas que envolvem agressão, raiva e seus fatores neuropsicológicos associados. Dito isso, considera-se que a sistematização dessas informações contribui na identificação e controle dos casos de TPB em homens, assim como colabora para o desenvolvimento científico do campo da psicopatologia em relação aos processos que envolvem tal patologia.

PALAVRAS-CHAVE: Transtorno da Personalidade Borderline. Transtorno da personalidade Limítrofe. Masculino. Fatores desencadeantes. Cognição. Neurobiologia. Comportamento social.
ABSTRACT । OBJECTIVE: To present and systematize the main scientific evidence regarding borderline personality disorder (BPD) in men. METHOD: During April 2021, there was an integrative review of the scientific literature on the subject in question, using the descriptors indexed in the DeCS: Borderline Personality Disorder; Male; Precipitating Factors; Cognition; Neurobiology; Social Behavior. To perform a search, the descriptors were combined in the Medline, Lilacs, and EBCS databases on the search site Pubmed and the Virtual Health Library - VHL. RESULTS: It was possible to identify some behavioral, mood, and neuropsychological changes in men with BPD. Among behavioral changes, the most prevalent is aggression (37.5\% of articles). Likewise, the mood alteration most commonly found was emotional dysregulation (12.5\% of the articles), very common in patients with BPD; similarly, the neuropsychological alterations with the highest number of findings involve alterations in the amygdala region (20.83\% of the articles), cortex (16.66\% of the articles), and the hippocampus (16.66\% of the articles), essential regions for mood control and decision making. CONCLUSION: It was possible to conclude that there are some behavioral, mood, and neuropsychological changes that are more prevalent in males, especially those that involve aggression, anger, and their associated neuropsychological factors. That said, it is considered that the systematization of this information contributes to the identification and control of cases of BPD in men and contributes to the scientific development of the field of psychopathology concerning the processes involving such pathology.

KEYWORDS: Borderline Personality Disorder. Male. Precipitating factors. Cognition. Neurobiology. Social behavior. 


\section{Introdução}

De acordo com Dalgalarrondo (2019), os transtornos de personalidade são uma mudança da personalidade do indivíduo, em que os comportamentos e as emoções são significativamente instáveis, por vez, podendo acometer em prejuízo a vários aspectos da vida do paciente e pessoas do convívio diário. Os transtornos de personalidades são divididos em três grupos (A, B, C), sendo o Transtorno de Personalidade Borderline (TPB) um dos quatro transtornos do grupo B, com base no Manual Diagnóstico e Estatístico dos Transtornos Mentais - DSM 5 (APA, 2014).

O transtorno de personalidade borderline ou transtorno de personalidade limítrofe (TPB), de acordo com o DSM-5 (APA, 2014), caracteriza-se por uma difusão de alterações comportamentais, emocionais e na autopercepção que, por sua vez, causam sofrimento ao indivíduo e acometem prejuízos nas relações interpessoais. Ainda segundo o manual, seus sintomas mais comuns são: relacionamentos interpessoais difusos, instabilidade afetiva, sentimento de vazio, medo de rejeição, raiva evidente e constante, automutilação e ideação suicida.

Etiologicamente falando, o transtorno de personalidade borderline é multifatorial, logo, sugere-se que tanto uma predisposição genética quanto fatores ambientais podem estar envolvidos em seu desenvolvimento. Sobre o último, os principais fatores que contribuem para seu desenvolvimento envolvem maus tratos na infância, desde físicos, sexuais à negligência, encontrados em aproximadamente $70 \%$ das pessoas que possuem o transtorno, assim como em outros casos, por exemplo separação, apego materno deficiente, inadequação com as regras familiares e abuso de substâncias na família (Chapman et al., 2021).
No geral, sugere-se que a prevalência média do transtorno da personalidade borderline na população é estimada em 1,6\%, não obstante possa chegar a 5,9\% (Chapman et al., 2021) e 6\% em contextos de atenção primária, cerca de $10 \%$ entre pacientes de ambulatórios de saúde mental e aproximadamente $20 \%$ entre pacientes psiquiátricos internados (Ellison et al., 2018). A prevalência do transtorno pode diminuir nas faixas etárias mais altas.

Ainda sobre sua prevalência, o transtorno da personalidade borderline é diagnosticado predominantemente em indivíduos do sexo feminino, atingindo cerca de $75 \%$ dos diagnósticos, dado esse corroborado, sobretudo, ao fato de que grande parte desse quantitativo de casos em maior número em mulheres estar estritamente ligado a um número reduzido de amostras resultantes da presença escassa de homens no ambiente clínico (APA, 2014, pp. 665-666). Então, como resultado disso, há um quantificado maior de estudos acerca das características e fatores do borderline em mulheres e assim, embora homens apresentem borderline, pouco é apresentado sobre suas características e fatores que o envolvem.

Desse modo, é, então, devido a uma nítida escassez de produção científica, sobretudo no eixo das produções brasileiras a respeito do transtorno de personalidade borderline em homens, que o presente artigo faz-se essencial para ampliar a produção nacional a respeito dessa temática, estimulando pesquisas nessa área e proporcionando um material atual e em português para os futuros pesquisadores.

Sendo assim, a partir de uma revisão integrativa realizada no período de abril de 2021, esse artigo tem como objetivo sistematizar as principais evidências científicas publicadas entre 2016 e 2021 acerca dos fatores que envolvem o transtorno de personalidade borderline em homens. 


\section{Método}

Através da elaboração de um estudo de revisão integrativa, instrumento da Prática Baseada em Evidências (PBE), esse artigo se propôs a demonstrar sistematicamente evidências científicas acerca das características e fatores que envolvem o transtorno de personalidade borderline em homens. A estruturação básica dessa revisão, segundo Souza et al. (2010), é realizada em seis etapas ordenadas da seguinte forma: (1) Identificação do tema e elaboração da pergunta; (2) Definição dos critérios de inclusão e exclusão; (3) Categorização do estudo; (4) Análise crítica dos estudos incluídos; (5) Discussão dos resultados; (6) Apresentação da revisão/síntese do conhecimento. A escolha da produção desse tipo de estudo foi permeada pelo caráter metodológico mais estruturado e definido, bem como por seu caráter ampliado em pesquisas de literatura, em que abre a possibilidade para a inserção de artigos observacionais e experimentais, assim como estudos de revisão (Souza et al., 2010).

O primeiro passo para o desenvolvimento da presente revisão partiu da construção do detalhamento metodológico no qual encontra-se a pergunta norteadora: "O Transtorno de Personalidade Borderline é presente em homens?". Em seguida, foi feito um levantamento no DeCS (Descritores em Ciências da Saúde), utilizando os descritores: Transtorno da Personalidade Borderline; Transtorno da Personalidade Limítrofe; Masculino; Fatores Desencadeantes; Cognição; Neurobiologia; Comportamento Social; e seus correspondentes na língua inglesa. Para a pesquisa, realizaram-se os seguintes cruzamentos: Transtorno da Personalidade Borderline (Borderline Personality Disorder) or Transtorno da Personalidade Limítrofe and Masculino (Male) or Fatores Desencadeantes (Precipitating Factors) or Cognição (Cognition) or Neurobiologia (Neurobiology) or Comportamento Social (Social Behavior). O levantamento da amostra para a realização desse estudo foi realizado nas bases de dados Medline, Lilacs e EBCS nos sites de Busca Pubmed e na Biblioteca Virtual em Saúde - BVS), no período de abril de 2021.

A eleição dos estudos se deu por meio dos seguintes critérios de inclusão: Artigos originais; Artigos de revisão; Ensaios teóricos; Relatos de experiência;
Ensaios clínicos; sem restrição quanto a língua. Além disso, também foram incluídos estudos que, embora os objetivos não tivessem relação com a presença do borderline em homens, apresentavam dados significativos que contribuíam para o desenvolvimento do estudo em questão. E apenas artigos publicados entre o período de 2016 e 2021.

Como critérios de exclusão, optou-se por excluir: livros; monografias; teses; dissertações; resenhas de livros; artigos de intervenções ou programa de tratamento; artigos que a amostra era formada apenas por mulheres, bem como artigos sem clareza metodológica; ou seja, artigos que não apresentavam objetivo ou conclusão de maneira clara ou condizente com a proposta do estudo em questão.

No processo de busca (identificação), primeiramente foram achados 1162 artigos no total, dos quais 271 foram eliminados por repetição no início da triagem. Após isso, prosseguindo com a triagem, 859 estudos foram excluídos após a leitura dos títulos e resumos, sendo descartados aqueles que mencionavam intervenções $(n=239)$; falavam de outro transtorno $(n=275)$; artigos que apresentavam apenas mulheres na amostra ( $n=290)$; artigos não disponíveis $(n=11)$; não apresentavam nenhuma contribuição para o objetivo do artigo $(n=44)$. Nessa etapa de leitura dos títulos e resumos, todos os autores leram de maneira independente cada título e resumo marcando a inclusão ou exclusão de cada artigo e, logo em seguida, realizou-se um cruzamento dessas informações juntamente ao debate acerca dos motivos de terem incluído ou excluído um determinado artigo. Seguidamente, foram considerados elegíveis 31 artigos restantes.

Por fim, os 31 estudos foram lidos integralmente, sendo excluídos 7 após análise da qualidade metodológica dos estudos; isto é, os 24 artigos restantes apresentavam de maneira clara as características e alterações do transtorno de personalidade borderline em homens, assim como indicação do objetivo e consideração final que corroboravam com o intuito desse estudo. Todo esse processo está exemplificado na Figura 1. 
Figura 1. Fluxograma de triagem e estratégia de busca dos artigos

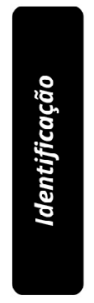

Estudos identificados através de pesquisas nas bases de dados PubMed/MEDLINE: 135 BVS/Lilacs/EBCS: 1026 fontes

$\mathrm{N}=1$

859 estudos excluídos após a leitura dos títulos e resumos

Mencionavam intervenções $(n=239)$

Falavam de outro transtorno $(n=275)$

Artigos que apresentavam apenas mulheres na amostra $(n=290)$

Artigos não disponíveis $(n=11)$

Estudos consideráveis elegíveis

$N=31$

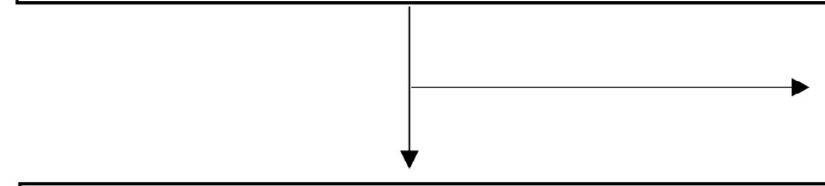

Estudos incluídos nesta revisão

$\mathrm{N}=24$

7 estudos excluídos após a leitura do texto na íntegra

Não apresentavam clareza metodológica $(n=4)$ Não apresentavam nenhuma contribuição para o objetivo do artigo $(n=3)$

Fonte: Os autores (2021).

\section{Resultados}

Essa revisão foi constituída de 24 publicações (Quadro 1) acerca das características e fatores que envolvem o transtorno de personalidade borderline em homens.

No Quadro 1, é possível verificar quais são os tipos de estudos mais encontrados para o desenvolvimento do presente artigo. Desses tipos de estudos, $41,70 \%(n=10)$ são artigos de revisão, $20,84 \%(n=5)$ artigos originais, $8,33 \%$ $(n=2)$ são estudos comparativos, 8,33\% ( $n=2)$ são estudos de coorte, 4,16\% ( $n=1)$ são estudos de caso controle, 4,16\% $(n=1)$ são estudos exploratórios, 4,16\% ( $n=1)$ são pesquisas aplicadas, 4,16\% (n=1) são estudos longitudinais e 4,16\% $(n=1)$ são estudos descritivos. Ainda no Quadro 1, também foi possível verificar um quantificado maior de artigos indexados no pubMED/Medline com 70,84\% ( $n=17$ ) em comparação ao BVS/Lilacs/Ebcs com 25\% ( $n=6)$ e 4,16\% ( $n=1$ ) dos estudos adicionais identificados através de outra fonte. No entanto, cabe ressaltar por motivos de transparência metodológica que, embora o BVS/Lilacs/Ebcs tenha apresentado apenas $25 \%$ do total de artigos, a maioria dos artigos dessa base de dados se encontravam em repetição com aqueles achados no pubMED/Medline, tal como foi possível identificar no fluxograma apresentado, em que muitos artigos foram excluídos por repetição.

Além disso, ao observar a quantidade de produções no período de 2016 a 2021 através do Quadro 1, constatou-se uma maior concentração de artigos publicados em 2019 ( $n=9)$, seguido de uma disposição com uma menor disparidade entre $2018(n=5)$ e $2017(n=5)$. Por fim, os anos de $2016(n=2), 2020(n=2)$ e $2021(n=1)$ concentram o menor quantitativo de artigos entre os anos investigados. Sendo o ano de 2019 o período de maior produção cientifica acerca da temática proposta. 
Quadro 1. Categorização dos artigos condizentes com o objetivo do estudo (continua)

\begin{tabular}{|c|c|c|c|c|c|c|}
\hline $\mathbf{N}^{\circ}$ & AUTOR (ES) & TÍTULO & INDEXADOR & PERIÓDICO & TIPO DO ESTUDO & ANO \\
\hline 1 & $\begin{array}{c}\text { Amad, Ali, Ramoz, } \\
\text { Nicolas, Peyre, } \\
\text { Hugo, Thomas, } \\
\text { Pierre, Gorwood, } \\
\text { Philip. }\end{array}$ & $\begin{array}{c}\text { FKBP5 gene variants and } \\
\text { borderline personality } \\
\text { disorder }\end{array}$ & BVS & $\begin{array}{l}\text { Journal of } \\
\text { Affective } \\
\text { Disorders }\end{array}$ & Artigo Original & 2019 \\
\hline 2 & $\begin{array}{l}\text { Bayes, A., \& } \\
\text { Parker, G. }\end{array}$ & $\begin{array}{l}\text { Borderline personality } \\
\text { disorder in men: A } \\
\text { literature review and } \\
\text { illustrative case vignettes }\end{array}$ & Pubmed & $\begin{array}{l}\text { Psychiatry } \\
\text { Research }\end{array}$ & Revisão & 2017 \\
\hline 3 & $\begin{array}{c}\text { Chen SF, Lin CL, } \\
\text { Wang LY, Wang } \\
\text { JH, Hsu CY, Shen } \\
\text { YC }\end{array}$ & $\begin{array}{l}\text { Borderline personality } \\
\text { disorder is associated } \\
\text { with an increased risk of } \\
\text { sexually. transmitted } \\
\text { infections: A nationwide } \\
\text { population-based cohort } \\
\text { study in Taiwan }\end{array}$ & BVS & $\begin{array}{l}\text { Sexually } \\
\text { Transmitted } \\
\text { Infections }\end{array}$ & Estudo de coorte & 2019 \\
\hline 4 & $\begin{array}{l}\text { Aquino Ferreira, } \\
\text { L. F., Queiroz } \\
\text { Pereira, F. H., Neri } \\
\text { Benevides, A., \& } \\
\text { Aguiar Melo, M. } \\
\text { C. }\end{array}$ & $\begin{array}{l}\text { Borderline personality } \\
\text { disorder and sexual } \\
\text { abuse: A systematic } \\
\text { review. }\end{array}$ & Pubmed & $\begin{array}{l}\text { Psychiatry } \\
\text { Research }\end{array}$ & Revisão & 2018 \\
\hline 5 & $\begin{array}{c}\text { Falcus, Craig, } \\
\text { Johnson, Darren }\end{array}$ & $\begin{array}{l}\text { The Violent Accounts of } \\
\text { Men Diagnosed with } \\
\text { Comorbid Antisocial and } \\
\text { Borderline Personality } \\
\text { Disorders. }\end{array}$ & BVS & $\begin{array}{l}\text { International } \\
\text { Journal of } \\
\text { Offender } \\
\text { Therapy and } \\
\text { Comparative } \\
\text { Criminology }\end{array}$ & Estudo descritivo & 2017 \\
\hline 6 & $\begin{array}{l}\text { Foxhall, M., } \\
\text { Hamilton- } \\
\text { Giachritsis, C., \& } \\
\text { Button, K. }\end{array}$ & $\begin{array}{l}\text { The link between } \\
\text { rejection sensitivity and } \\
\text { borderline personality } \\
\text { disorder: A systematic } \\
\text { review and meta- } \\
\text { analysis. }\end{array}$ & Pubmed & $\begin{array}{l}\text { Iranian Journal } \\
\text { of Clinical } \\
\text { Psychology }\end{array}$ & Revisão & 2019 \\
\hline 7 & $\begin{array}{l}\text { Frías, Álvaro; } \\
\text { Palma, Carol; } \\
\text { Farriols, Núria; } \\
\text { González, Laura. }\end{array}$ & $\begin{array}{c}\text { Sexuality-related issues } \\
\text { in borderline personality } \\
\text { disorder: A } \\
\text { comprehensive review }\end{array}$ & BVS & $\begin{array}{c}\text { Personal } \\
\text { Mental Health. }\end{array}$ & Revisão & 2016 \\
\hline 8 & $\begin{array}{c}\text { Godbout, } \\
\text { Natacha; Daspe, } \\
\text { Marie-Ėve; Runtz, } \\
\text { Marsha; Cyr, } \\
\text { Gaëlle; Briere }\end{array}$ & $\begin{array}{l}\text { Childhood maltreatment, } \\
\text { attachment, and } \\
\text { borderline personality- } \\
\text { related symptoms: } \\
\text { Gender-specific } \\
\text { structural equation } \\
\text { models. }\end{array}$ & BVS & $\begin{array}{l}\text { Psychological } \\
\text { Trauma: } \\
\text { Theory, } \\
\text { Research, } \\
\text { Practice, and } \\
\text { Policy }\end{array}$ & Pesquisa aplicada & 2019 \\
\hline 9 & $\begin{array}{l}\text { Herpertz, Sabine } \\
\text { C; Nagy, Krisztina; } \\
\text { Veltzhöffer, Kai; } \\
\text { Schmitt, Ruth; } \\
\text { Mancke, Falk; } \\
\text { Schmahl, } \\
\text { Christian; } \\
\text { Bertsch, Katja. }\end{array}$ & $\begin{array}{c}\text { Brain Mechanisms } \\
\text { Underlying Reactive } \\
\text { Aggression in Borderline } \\
\text { Personality. Disorder-Sex } \\
\text { Matters. }\end{array}$ & BVS & $\begin{array}{l}\text { Biological } \\
\text { Psychiatry: A } \\
\text { Journal if } \\
\text { Pasychiatric } \\
\text { Neuroscience } \\
\text { and } \\
\text { Therapeutics }\end{array}$ & Artigo Original & 2017 \\
\hline 10 & $\begin{array}{l}\text { Holthausen, S. B., } \\
\text { \& Habel, U. }\end{array}$ & $\begin{array}{c}\text { Sex Differences in } \\
\text { Personality Disorders. }\end{array}$ & Pubmed & $\begin{array}{l}\text { Current } \\
\text { Psychiatry } \\
\text { Reports } \\
\text { provides }\end{array}$ & Revisão & 2018 \\
\hline
\end{tabular}


Quadro 1. Categorização dos artigos condizentes com o objetivo do estudo (continuação)

\begin{tabular}{|c|c|c|c|c|c|c|}
\hline $\mathbf{N}^{\circ}$ & AUTOR (ES) & TÍTULO & INDEXADOR & PERIÓDICO & TIPO DO ESTUDO & ANO \\
\hline 11 & $\begin{array}{c}\text { Kaess, Michael; } \\
\text { Whittle, Sarah; } \\
\text { Simmons, Julian } \\
\text { G; Jovev, Martina; } \\
\text { Allen, Nicholas B; } \\
\text { Chanen, Andrew } \\
\text { M. } \\
\end{array}$ & $\begin{array}{l}\text { The Interaction of } \\
\text { Childhood Maltreatment, } \\
\text { Sex, and Borderline } \\
\text { Personality. Features in } \\
\text { the Prediction of the } \\
\text { Cortisol Awakening } \\
\text { Response in Adolescents. }\end{array}$ & BVS & $\begin{array}{l}\text { Psychopatholog } \\
\text { y: Mind, } \\
\text { behavior, } \\
\text { biology, and } \\
\text { therapies }\end{array}$ & $\begin{array}{c}\text { Estudo } \\
\text { Longitudinal }\end{array}$ & 2017 \\
\hline 12 & $\begin{array}{l}\text { Kaplan, Bahar; } \\
\text { Yazici Gulec, } \\
\text { Medine; Gica, } \\
\text { Sakir; Gulec, } \\
\text { Huseyin. }\end{array}$ & $\begin{array}{l}\text { The association between } \\
\text { neurocognitive } \\
\text { functioning and clinical } \\
\text { features of borderline } \\
\text { personality disorder. }\end{array}$ & BVS & $\begin{array}{l}\text { Brazilian } \\
\text { Journal of } \\
\text { Psychiatry }\end{array}$ & $\begin{array}{l}\text { Um estudo caso- } \\
\text { controle }\end{array}$ & 2020 \\
\hline 13 & $\begin{array}{c}\text { Khoury, JE; } \\
\text { Pechtel, P; } \\
\text { Andersen, CM; } \\
\text { Teicher, M H; } \\
\text { Lyons-Ruth, K. }\end{array}$ & $\begin{array}{c}\text { Relations among } \\
\text { maternal withdrawal in } \\
\text { infancy, borderline } \\
\text { features, suicidality/self- } \\
\text { injury, and adult } \\
\text { hippocampal volume: A } \\
\text { 30-year longitudinal } \\
\text { study. }\end{array}$ & BVS & $\begin{array}{l}\text { Behavioural } \\
\text { Brain Research }\end{array}$ & Estudo de coorte & 2019 \\
\hline 14 & $\begin{array}{l}\text { Lu, Wei-Hsin; } \\
\text { Wang, Peng-Wei; } \\
\text { Ko, Chih-Hung; } \\
\text { Hsiao, Ray C; Liu, } \\
\text { Tai-Ling; Yen, } \\
\text { Cheng-Fang. }\end{array}$ & $\begin{array}{l}\text { Differences in mental } \\
\text { health among young } \\
\text { adults with borderline } \\
\text { personality. symptoms of } \\
\text { various severities. }\end{array}$ & BVS & $\begin{array}{l}\text { Psychopatholog } \\
\text { y: International } \\
\text { Journal of } \\
\text { Descriptive and } \\
\text { Experimental } \\
\text { Psychopatholog } \\
y\end{array}$ & Artigo Original & 2018 \\
\hline 15 & $\begin{array}{l}\text { Mancke, Falk; } \\
\text { Herpertz, Sabine } \\
\text { C; Hirjak, Dusan; } \\
\text { Knies, Rebekka; } \\
\text { Bertsch, Katja }\end{array}$ & $\begin{array}{l}\text { Amygdala structure and } \\
\text { aggressiveness in } \\
\text { borderline personality } \\
\text { disorder. }\end{array}$ & BVS & $\begin{array}{c}\text { European } \\
\text { Archives of } \\
\text { Psychiatry and } \\
\text { Clinical } \\
\text { Neuroscience }\end{array}$ & Artigo Original & 2018 \\
\hline 16 & $\begin{array}{c}\text { Nascimento, } \\
\text { Rodrigo Barbosa; } \\
\text { Cerqueira, } \\
\text { Gabriela de Lima; } \\
\text { Filho, Emanuel } \\
\text { Santos de Araújo. }\end{array}$ & $\begin{array}{c}\text { Características e } \\
\text { alterações } \\
\text { neuropsicológicas no } \\
\text { Transtorno de } \\
\text { Personalidade } \\
\text { Borderline: uma revisão } \\
\text { de literatura }\end{array}$ & $\begin{array}{c}\text { Google } \\
\text { Acadêmico }\end{array}$ & $\begin{array}{l}\text { Revista Ibero- } \\
\text { Americana de } \\
\text { Humanidades, } \\
\text { Ciências e } \\
\text { Educação }\end{array}$ & Revisão & 2021 \\
\hline 17 & $\begin{array}{c}\text { Navarro-Gómez, } \\
\text { S., Frías, Á., \& } \\
\text { Palma, C. }\end{array}$ & $\begin{array}{l}\text { Romantic Relationships } \\
\text { of People with Borderline } \\
\text { Personality: A Narrative } \\
\text { Review. }\end{array}$ & Pubmed & $\begin{array}{l}\text { Psychopatholog } \\
\text { y: International } \\
\text { Journal of } \\
\text { Descriptive and } \\
\text { Experimental } \\
\text { Psychopatholog } \\
\text { y } \\
\end{array}$ & Revisão & 2017 \\
\hline 18 & $\begin{array}{l}\text { Sher, L; Rutter, S } \\
\text { B; New, AS; } \\
\text { Siever,LJ; Hazlett, } \\
\text { E A. }\end{array}$ & $\begin{array}{l}\text { Gender differences and } \\
\text { similarities in aggression, } \\
\text { suicidal behaviour, and } \\
\text { psychiatric comorbidity } \\
\text { in borderline personality } \\
\text { disorder }\end{array}$ & BVS & $\begin{array}{c}\text { Acta } \\
\text { Psychiatrica } \\
\text { Scandinavica }\end{array}$ & $\begin{array}{c}\text { Estudo } \\
\text { Comparativo }\end{array}$ & 2019 \\
\hline 19 & $\begin{array}{l}\text { Steele, Kayla R; } \\
\text { Townsend, } \\
\text { Michelle L; } \\
\text { Grenyer, Brin FS. }\end{array}$ & $\begin{array}{l}\text { Parenting and } \\
\text { personality disorder: An } \\
\text { overview and meta- } \\
\text { synthesis of systematic } \\
\text { reviews. }\end{array}$ & BVS & Plos one & Revisão & 2019 \\
\hline 20 & $\begin{array}{l}\text { Thomas, N., } \\
\text { Gurvich, C., } \\
\text { Hudaib, A. R., } \\
\text { Gavrilidis, E., \& } \\
\text { Kulkarni, J. }\end{array}$ & $\begin{array}{c}\text { Systematic review and } \\
\text { meta-analysis of basal } \\
\text { cortisol levels in } \\
\text { Borderline Personality } \\
\text { Disorder compared to } \\
\text { non-psychiatric controls. }\end{array}$ & Pubmed & $\begin{array}{l}\text { Psychoneuroen } \\
\text { docrinology }\end{array}$ & Revisão & 2019 \\
\hline 21 & $\begin{array}{l}\text { Van den Brink, } \\
\text { Chantal; Harte, } \\
\text { Joke M; Denzel, A } \\
\text { Dorina }\end{array}$ & $\begin{array}{l}\text { Men and women with } \\
\text { borderline personality } \\
\text { disorder resident in } \\
\text { Dutch special psychiatric } \\
\text { units in prisons: A } \\
\text { descriptive and } \\
\text { comparative study. }\end{array}$ & BVS & $\begin{array}{l}\text { CBMH:Criminal } \\
\text { behavior and } \\
\text { mental health }\end{array}$ & $\begin{array}{c}\text { Estudo } \\
\text { comparativo }\end{array}$ & 2018 \\
\hline
\end{tabular}


Quadro 1. Categorização dos artigos condizentes com o objetivo do estudo (conclusão)

\begin{tabular}{|c|c|c|c|c|c|c|}
\hline $\mathbf{N}^{\circ}$ & AUTOR (ES) & TÍTULO & INDEXADOR & PERIÓDICO & TIPO DO ESTUDO & ANO \\
\hline 22 & $\begin{array}{c}\text { Winsper, } \\
\text { Catherine; } \\
\text { Marwaha, Steven; } \\
\text { Lereya, Suzet } \\
\text { Tanya; } \\
\text { Thompson, } \\
\text { Andrew; Eyden, } \\
\text { Julie; Singh, } \\
\text { Swaran P. }\end{array}$ & $\begin{array}{l}\text { A systematic review of } \\
\text { the neurobiological } \\
\text { underpinnings of } \\
\text { borderline personality } \\
\text { disorder (BPD) in } \\
\text { childhood and } \\
\text { adolescence. }\end{array}$ & BVS & $\begin{array}{l}\text { Reviews in the } \\
\text { Neurosciences }\end{array}$ & Revisão & 2016 \\
\hline 23 & $\begin{array}{l}\text { Yalch, Matthew } \\
\text { M; Levendosky, } \\
\text { Alytia A }\end{array}$ & $\begin{array}{c}\text { Influence of betrayal } \\
\text { trauma on borderline } \\
\text { personality disorder } \\
\text { traits }\end{array}$ & BVS & $\begin{array}{c}\text { Journal of } \\
\text { Trauma \& } \\
\text { Dissociation }\end{array}$ & Artigo Original & 2019 \\
\hline 24 & $\begin{array}{l}\text { Zhang, Min; Liu, } \\
\text { Na; Chen, } \\
\text { Haocheng; Zhang, } \\
\text { Ning. }\end{array}$ & $\begin{array}{l}\text { Oxytocin receptor gene, } \\
\text { childhood maltreatment } \\
\text { and borderline } \\
\text { personality, disorder } \\
\text { features among male } \\
\text { inmates in China }\end{array}$ & BVS & BMC Psychiatry & $\begin{array}{l}\text { Estudo } \\
\text { Exploratório }\end{array}$ & 2020 \\
\hline
\end{tabular}

Fonte: Os autores (2021).

Embora os artigos coletados para a realização dessa revisão já estejam apresentados no Quadro 1, no Quadro 2 foi apresentado um maior detalhamento dessa amostra de artigos com objetivo de tornar o mais transparente possível quais artigos foram selecionados.

Quadro 2. Detalhamento e transparência metodológica dos artigos dispostos no Quadro 1 (continua)

\begin{tabular}{|c|c|c|c|c|}
\hline $\mathbf{N}^{\circ}$ & TÍTULO & SOBRE O ARTIGO & POPULAÇÃO & ANO \\
\hline 1 & $\begin{array}{l}\text { FKBP5 gene variants } \\
\text { and borderline } \\
\text { personality disorder }\end{array}$ & $\begin{array}{l}\text { O objetivo do presente estudo foi } \\
\text { investigar a contribuição de } \\
\text { diferentes polimorfismos de FKBP5 e } \\
\text { explorar o efeito modulador do } \\
\text { abuso infantil de forma } \\
\text { independente }\end{array}$ & $\begin{array}{l}\text { Cinco FKBP5 (um co-chaperone } \\
\text { do receptor de glicocorticóide) } \\
\text { SNPs (rs3800373, rs9296158, } \\
\text { rs737054, rs1360780, } \\
\text { rs9470080) foram genotipados } \\
\text { em uma amostra de } 101 \\
\text { pacientes caucasianos não } \\
\text { relacionados com DBP e } 111 \\
\text { controles saudáveis pareados } \\
\text { etnicamente. A interação entre } \\
\text { polimorfismos FKBP5 e trauma } \\
\text { infantil também foi testada. }\end{array}$ & 2019 \\
\hline 2 & $\begin{array}{l}\text { Borderline personality } \\
\text { disorder in men: A } \\
\text { literature review and } \\
\text { illustrative case } \\
\text { vignettes }\end{array}$ & $\begin{array}{l}\text { O objetivo é revisar a literatura } \\
\text { relevante sobre transtorno de } \\
\text { personalidade limítrofe (TPB) em } \\
\text { homens e vincular esses achados a } \\
\text { vinhetas de casos. }\end{array}$ & $x$ & 2017 \\
\hline 3 & $\begin{array}{l}\text { Borderline personality } \\
\text { disorder is associated } \\
\text { with an increased risk } \\
\text { of sexually. } \\
\text { transmitted infections: } \\
\text { A nationwide } \\
\text { population-based } \\
\text { cohort study in Taiwan }\end{array}$ & $\begin{array}{l}\text { O estudo visa determinar se o TPB } \\
\text { está associado a um risco } \\
\text { aumentado de IST subsequente em } \\
\text { Taiwan. }\end{array}$ & $\begin{array}{c}669 \text { pacientes com DBP e } 2676 \\
\text { controles pareados por sexo e } \\
\text { idade foram inscritos entre } \\
2000 \text { e } 2012 \text { e acompanhados } \\
\text { até o final de } 2013 \text { usando o } \\
\text { Banco de Dados de Pesquisa } \\
\text { de Seguro de Saúde Nacional } \\
\text { de Taiwan }\end{array}$ & 2019 \\
\hline
\end{tabular}


Quadro 2. Detalhamento e transparência metodológica dos artigos dispostos no Quadro 1 (continuação)

\begin{tabular}{|c|c|c|c|c|}
\hline $\mathbf{N}^{\circ}$ & $\begin{array}{c}\text { TÍTULO } \\
\end{array}$ & SOBRE O ARTIGO & POPULAÇÃO & ANO \\
\hline 4 & $\begin{array}{l}\text { Borderline personality } \\
\text { disorder and sexual } \\
\text { abuse: A systematic } \\
\text { review. }\end{array}$ & $\begin{array}{l}\text { Este artigo objetivou investigar o } \\
\text { abuso sexual (incluindo a idade } \\
\text { adulta) como um preditor de } \\
\text { diagnóstico de DBP, apresentação } \\
\text { clínica e prognóstico. }\end{array}$ & $x$ & 2018 \\
\hline 5 & $\begin{array}{l}\text { The Violent Accounts } \\
\text { of Men Diagnosed } \\
\text { with Comorbid } \\
\text { Antisocial and } \\
\text { Borderline Personality } \\
\text { Disorders. }\end{array}$ & $\begin{array}{l}\text { Este estudo explorou os relatos de } \\
\text { crimes violentos de prisioneiros } \\
\text { condenados à prisão perpétua com } \\
\text { diagnóstico de transtorno de } \\
\text { personalidade antissocial (ASPD) e } \\
\text { transtorno de personalidade } \\
\text { limítrofe (TPB) comórbido. O objetivo } \\
\text { do presente estudo foi obter o } \\
\text { conhecimento clínico necessário } \\
\text { sobre os mecanismos envolvidos } \\
\text { nesse grupo específico de agressores } \\
\text { do uso da violência contra outras } \\
\text { pessoas. }\end{array}$ & $\begin{array}{l}\text { Seis criminosos adultos com } \\
\text { transtorno de personalidade } \\
\text { do sexo masculino foram } \\
\text { entrevistados por meio de uma } \\
\text { programação de entrevista } \\
\text { semiestruturada para } \\
\text { comparar relatos de ofensas } \\
\text { individuais. }\end{array}$ & 2017 \\
\hline 6 & $\begin{array}{l}\text { The link between } \\
\text { rejection sensitivity } \\
\text { and borderline } \\
\text { personality disorder: A } \\
\text { systematic review and } \\
\text { meta-analysis. }\end{array}$ & $\begin{array}{l}\text { Pessoas com Transtorno de } \\
\text { Personalidade Limítrofe (TPB) podem } \\
\text { apresentar maior sensibilidade à } \\
\text { rejeição (RS), uma disposição que se } \\
\text { desenvolve a partir de experiências } \\
\text { repetidas de rejeição na infância. } \\
\text { Não se sabe se o modelo RS } \\
\text { completo é responsável pelas } \\
\text { experiências cognitivo-afetivas } \\
\text { comuns no TPB. Esta revisão } \\
\text { sistemática se estende a revisões } \\
\text { anteriores, primeiro avaliando a } \\
\text { ligação entre experiências de } \\
\text { rejeição na infância e RS em adultos } \\
\text { e, em segundo lugar, considerando a } \\
\text { ligação entre DBP e RS em amostras } \\
\text { não clínicas e clínicas }\end{array}$ & $x$ & 2019 \\
\hline 7 & $\begin{array}{l}\text { Sexuality-related } \\
\text { issues in borderline } \\
\text { personality disorder: A } \\
\text { comprehensive review }\end{array}$ & $\begin{array}{l}\text { A sexualidade é um tanto } \\
\text { negligenciada na pesquisa clínica } \\
\text { sobre transtorno de personalidade } \\
\text { limítrofe (TPB). }\end{array}$ & $x$ & 2016 \\
\hline 8 & $\begin{array}{l}\text { Childhood } \\
\text { maltreatment, } \\
\text { attachment, and } \\
\text { borderline } \\
\text { personality-related } \\
\text { symptoms: Gender- } \\
\text { specific structural } \\
\text { equation models. }\end{array}$ & $\begin{array}{l}\text { O objetivo do presente estudo foi } \\
\text { examinar um modelo integrativo de } \\
\text { maus-tratos e apego inseguro } \\
\text { maternos e paternos na infância e } \\
\text { como eles preveem sintomas } \\
\text { relacionados à personalidade } \\
\text { limítrofe }\end{array}$ & $\begin{array}{l}\text { A amostra foi composta por } \\
954 \text { participantes que } \\
\text { completaram medidas de } \\
\text { autorrelato de maus-tratos } \\
\text { parentais durante a infância, } \\
\text { segurança do apego e sintomas } \\
\text { relacionados ao trauma. }\end{array}$ & 2019 \\
\hline 9 & $\begin{array}{l}\text { Brain Mechanisms } \\
\text { Underlying Reactive } \\
\text { Aggression in } \\
\text { Borderline } \\
\text { Personality. Disorder- } \\
\text { Sex Matters. }\end{array}$ & $\begin{array}{l}\text { Este estudo teve como objetivo } \\
\text { investigar o processamento de 1) } \\
\text { raiva, sentimentos no contexto de } \\
\text { rejeição social e 2) baseados na } \\
\text { raiva, comportamento agressivo } \\
\text { reativo em pacientes com DBP do } \\
\text { sexo feminino e masculino, e, assim, } \\
\text { pela primeira vez, diferenciar } \\
\text { explicitamente entre uma falha na } \\
\text { regulação da emoção e falha no } \\
\text { controle comportamental em } \\
\text { estados de excitação emocional no } \\
\text { TPB. }\end{array}$ & $\begin{array}{l}\text { Trinta e três pacientes do sexo } \\
\text { feminino e } 23 \text { do sexo } \\
\text { masculino com DBP e } 30 \\
\text { mulheres saudáveis e } 26 \\
\text { homens saudáveis } \\
\text { participaram deste estudo de } \\
\text { ressonância magnética } \\
\text { funcional. }\end{array}$ & 2017 \\
\hline
\end{tabular}


Quadro 2. Detalhamento e transparência metodológica dos artigos dispostos no Quadro 1 (continuação)

\begin{tabular}{|c|c|c|c|c|}
\hline $\mathbf{N}^{\circ}$ & TÍTULO & SOBRE O ARTIGO & POPULAÇÃO & ANO \\
\hline 10 & $\begin{array}{l}\text { Sex Differences in } \\
\text { Personality Disorders. }\end{array}$ & $\begin{array}{l}\text { Esta revisão tem como objetivo } \\
\text { fornecer uma visão geral da } \\
\text { literatura atual sobre diferenças } \\
\text { sexuais em transtornos de } \\
\text { personalidade e destacar o potencial } \\
\text { das abordagens dimensionais. }\end{array}$ & $\mathrm{x}$ & 2018 \\
\hline 11 & $\begin{array}{l}\text { The Interaction of } \\
\text { Childhood } \\
\text { Maltreatment, Sex, } \\
\text { and Borderline } \\
\text { Personality. Features } \\
\text { in the Prediction of } \\
\text { the Cortisol } \\
\text { Awakening Response } \\
\text { in Adolescents. }\end{array}$ & $\begin{array}{l}\text { O estudo teve como objetivo } \\
\text { investigar maus tratos na infância, } \\
\text { sexo e sintomas de transtorno de } \\
\text { personalidade limítrofe (DBP) como } \\
\text { preditores prospectivos da } \\
\text { reatividade do eixo hipotálamo- } \\
\text { pituitária-adrenal (HPA) em } \\
\text { adolescentes. }\end{array}$ & $\begin{array}{l}\text { Uma amostra de } 69 \\
\text { adolescentes ( } 30 \text { mulheres e } 39 \\
\text { homens) foi selecionada a } \\
\text { partir de um estudo } \\
\text { longitudinal maior de } \\
\text { desenvolvimento adolescente e } \\
\text { avaliada em } 3 \text { momentos. }\end{array}$ & 2017 \\
\hline 12 & $\begin{array}{l}\text { The association } \\
\text { between } \\
\text { neurocognitive } \\
\text { functioning and } \\
\text { clinical features of } \\
\text { borderline personality } \\
\text { disorder. }\end{array}$ & $\begin{array}{l}\text { O objetivo do presente estudo foi } \\
\text { investigar a relação entre perfis } \\
\text { neurocognitivos e manifestações } \\
\text { clínicas, correlacionando o Verbal } \\
\text { Memory Processes Test (VMPT) e } \\
\text { uma versão computadorizada da } \\
\text { Cambridge Neurophysiological } \\
\text { Assessment Battery (CANTAB). }\end{array}$ & $\begin{array}{l}\text { Quarenta e cinco pacientes } \\
\text { com diagnóstico de DBP e } 35 \\
\text { voluntários saudáveis foram } \\
\text { incluídos no estudo. }\end{array}$ & 2020 \\
\hline 13 & $\begin{array}{l}\text { Relations among } \\
\text { maternal withdrawal } \\
\text { in infancy, borderline } \\
\text { features, } \\
\text { suicidality/self-injury, } \\
\text { and adult } \\
\text { hippocampal volume: } \\
\text { A 30-year longitudinal } \\
\text { study. }\end{array}$ & $\begin{array}{c}\text { No contexto de um estudo } \\
\text { longitudinal de } 30 \text { anos, avaliamos } \\
\text { associações entre abstinência } \\
\text { materna na infância, volume do } \\
\text { hipocampo e características de DBP } \\
\text { na idade adulta. }\end{array}$ & $\begin{array}{c}\text { O volume hipocampal foi } \\
\text { avaliado em } 18 \text { adultos }(29,33 \pm \\
0.49 \text { anos) avaliada quanto à } \\
\text { qualidade do cuidado aos } 18 \\
\text { meses ( } \mathrm{M}=18,55 \text { meses, } \mathrm{DP}= \\
1,21 \text { meses) e seguida } \\
\text { longitudinalmente até a idade } \\
\text { de } 29 \text { anos. }\end{array}$ & 2019 \\
\hline 14 & $\begin{array}{l}\text { Differences in mental } \\
\text { health among young } \\
\text { adults with borderline } \\
\text { personality. } \\
\text { symptoms of various } \\
\text { severities. }\end{array}$ & $\begin{array}{l}\text { Este estudo examinou as diferenças } \\
\text { na saúde mental e problemas } \\
\text { comportamentais entre jovens } \\
\text { adultos com sintomas de } \\
\text { personalidade limítrofe de várias } \\
\text { gravidades. }\end{array}$ & $\begin{array}{l}500 \text { estudantes universitários } \\
\text { participaram deste estudo. Os } \\
\text { sintomas de personalidade } \\
\text { limítrofe foram avaliados } \\
\text { usando a versão taiwanesa da } \\
\text { Lista de sintomas limítrofes } \\
\text { (BSL-23). }\end{array}$ & 2018 \\
\hline 15 & $\begin{array}{l}\text { Amygdala structure } \\
\text { and aggressiveness in } \\
\text { borderline personality } \\
\text { disorder. }\end{array}$ & $\begin{array}{c}\text { No presente estudo, portanto, } \\
\text { investigamos uma amostra mista de } \\
\text { sexo de pacientes com DBP e } \\
\text { voluntários saudáveis e aplicamos } \\
\text { um método de segmentação } \\
\text { automatizado que permite o estudo } \\
\text { de ambas as alterações no volume } \\
\text { da amígdala e a forma localizada da } \\
\text { amígdala. }\end{array}$ & $\begin{array}{l}\text { Um total de } 60 \text { pacientes } \\
\text { adultos sem medicação com } \\
\text { uma corrente Segmentações } \\
\text { de dois pacientes masculinos } \\
\text { com DBP falharam e foram } \\
\text { excluídos, resultando no } \\
\text { número total de } 21 \text { pacientes } \\
\text { masculinos com DBP. O grupo } \\
\text { de controle consistiu de } 51 \\
\text { voluntários saudáveis que } \\
\text { nunca receberam um } \\
\text { diagnóstico psiquiátrico ou se } \\
\text { submeteram a qualquer } \\
\text { procedimento psicológico / } \\
\text { psiquiátrico tratamento. }\end{array}$ & 2018 \\
\hline 16 & $\begin{array}{l}\text { Características e } \\
\text { alterações } \\
\text { neuropsicológicas no } \\
\text { Transtorno de } \\
\text { Personalidade } \\
\text { Borderline: uma } \\
\text { revisão da literatura }\end{array}$ & $\begin{array}{l}\text { Este estudo objetivou apresentar } \\
\text { evidências científicas e sistematizar } \\
\text { as principais compreensões da } \\
\text { literatura científica publicadas entre } \\
2010 \text { e } 2021 \text { acerca das } \\
\text { características e alterações } \\
\text { neuropsicológicas presentes no TPB. }\end{array}$ & $\mathrm{x}$ & 2021 \\
\hline
\end{tabular}


Quadro 2. Detalhamento e transparência metodológica dos artigos dispostos no Quadro 1 (continuação)

\begin{tabular}{|c|c|c|c|c|}
\hline $\mathbf{N}^{\circ}$ & TÍTULO & SOBRE O ARTIGO & POPULAÇÃO & ANO \\
\hline 17 & $\begin{array}{l}\text { Romantic } \\
\text { Relationships of } \\
\text { People with } \\
\text { Borderline } \\
\text { Personality: A } \\
\text { Narrative Review. }\end{array}$ & $\begin{array}{l}\text { O objetivo desta revisão narrativa foi } \\
\text { sintetizar os resultados empíricos } \\
\text { sobre esta questão. }\end{array}$ & $x$ & 2017 \\
\hline 18 & $\begin{array}{l}\text { Gender differences } \\
\text { and similarities in } \\
\text { aggression, suicidal } \\
\text { behaviour, and } \\
\text { psychiatric } \\
\text { comorbidity in } \\
\text { borderline personality } \\
\text { disorder }\end{array}$ & $\begin{array}{l}\text { Examinamos as diferenças de gênero } \\
\text { e semelhanças na agressão, } \\
\text { impulsividade, comportamento } \\
\text { suicida e comorbidade psiquiátrica } \\
\text { em homens e mulheres com } \\
\text { transtorno de personalidade } \\
\text { limítrofe (TPB) em comparação com } \\
\text { controles saudáveis. }\end{array}$ & $\begin{array}{l}\text { Uma amostra da comunidade } \\
\text { de } 511 \text { participantes (controles } \\
\text { saudáveis: } 81 \text { homens e } 82 \\
\text { mulheres; pacientes com DBP: } \\
145 \text { homens e } 203 \text { mulheres) } \\
\text { foi rigorosamente } \\
\text { caracterizada por meio de } \\
\text { entrevistas diagnósticas } \\
\text { estruturadas e avaliações da } \\
\text { gravidade dos sintomas. }\end{array}$ & 2019 \\
\hline 19 & $\begin{array}{l}\text { Parenting and } \\
\text { personality disorder: } \\
\text { An overview and } \\
\text { meta-synthesis of } \\
\text { systematic reviews. }\end{array}$ & $\begin{array}{l}\text { Nosso objetivo principal foi resumir } \\
\text { as evidências sobre a relação entre } \\
\text { paternidade e transtorno de } \\
\text { personalidade, auxiliando os } \\
\text { tomadores de decisão clínicos a } \\
\text { traduzir esta pesquisa em políticas e } \\
\text { práticas clínicas. }\end{array}$ & $x$ & 2019 \\
\hline 20 & $\begin{array}{l}\text { Systematic review and } \\
\text { meta-analysis of basal } \\
\text { cortisol levels in } \\
\text { Borderline Personality } \\
\text { Disorder compared to } \\
\text { non-psychiatric } \\
\text { controls. }\end{array}$ & $\begin{array}{c}\text { O transtorno de personalidade } \\
\text { limítrofe (TPB) é um transtorno } \\
\text { mental prevalente, complexo e sério } \\
\text { que envolve vários sintomas e } \\
\text { comportamento mal adaptativo. Os } \\
\text { mecanismos psicobiológicos } \\
\text { subjacentes envolvidos ainda não } \\
\text { são totalmente compreendidos, mas } \\
\text { evidências crescentes indicam que as } \\
\text { alterações na atividade do eixo de } \\
\text { estresse hipotálamo-pituitária- } \\
\text { adrenal (HPA) podem contribuir para } \\
\text { o DBP. }\end{array}$ & $x$ & 2019 \\
\hline 21 & $\begin{array}{l}\text { Men and women with } \\
\text { borderline personality } \\
\text { disorder resident in } \\
\text { Dutch special } \\
\text { psychiatric units in } \\
\text { prisons: A descriptive } \\
\text { and comparative } \\
\text { study. }\end{array}$ & $\begin{array}{l}\text { Descrever as características de } \\
\text { homens e mulheres com transtorno } \\
\text { de personalidade borderline em } \\
\text { unidades psiquiátricas especiais em } \\
\text { prisões holandesas em três } \\
\text { domínios: prevalência de abuso } \\
\text { infantil, comorbidade de transtorno } \\
\text { de personalidade borderline com } \\
\text { outros transtornos e sintomas } \\
\text { clínicos. }\end{array}$ & $\begin{array}{l}167 \text { pessoas foram designadas } \\
\text { para este estudo com base em } \\
\text { diagnósticos do Manual } \\
\text { Diagnóstico e Estatístico de } \\
\text { Transtornos Mentais, quinta } \\
\text { edição (DSM-5) recuperados de } \\
\text { registros. Outros diagnósticos } \\
\text { do DSM-5 também foram } \\
\text { registrados. }\end{array}$ & 2018 \\
\hline 22 & $\begin{array}{l}\text { A systematic review of } \\
\text { the neurobiological } \\
\text { underpinnings of } \\
\text { borderline personality } \\
\text { disorder (BPD) in } \\
\text { childhood and } \\
\text { adolescence. }\end{array}$ & $\begin{array}{c}\text { Nesta revisão, apresentamos e } \\
\text { avaliamos criticamente as evidências } \\
\text { sobre a neurobiologia do TPB na } \\
\text { infância e adolescência, comparamos } \\
\text { essas evidências com a literatura } \\
\text { adulta e contextualizamos dentro de } \\
\text { uma estrutura de } \\
\text { neurodesenvolvimento. }\end{array}$ & $x$ & 2016 \\
\hline 23 & $\begin{array}{l}\text { Influence of betrayal } \\
\text { trauma on borderline } \\
\text { personality disorder } \\
\text { traits }\end{array}$ & $\begin{array}{c}\text { Neste estudo, examinamos a } \\
\text { influência de experiências } \\
\text { traumáticas com vários níveis de } \\
\text { traição no TPB avaliados por meio de } \\
\text { traços de personalidade mal } \\
\text { adaptativos. }\end{array}$ & $\begin{array}{l}\text { Em uma amostra de } \\
\text { estudantes universitários ( } \mathrm{N}= \\
\text { 915) usando uma abordagem } \\
\text { bayesiana para modelagem de } \\
\text { equações estruturais }\end{array}$ & 2019 \\
\hline
\end{tabular}


Quadro 2. Detalhamento e transparência metodológica dos artigos dispostos no Quadro 1 (conclusão)

\begin{tabular}{|c|c|c|c|c|}
\hline $\mathbf{N}^{0}$ & TÍTULO & SOBRE O ARTIGO & POPULAÇÃO & ANO \\
\hline 24 & $\begin{array}{l}\text { Oxytocin receptor } \\
\text { gene, childhood } \\
\text { maltreatment and } \\
\text { borderline personality, } \\
\text { disorder features } \\
\text { among male inmates } \\
\text { in China }\end{array}$ & $\begin{array}{l}\text { O objetivo deste estudo é explorar } \\
\text { ainda mais os efeitos interativos } \\
\text { entre os polimorfismos do gene } \\
\text { OXTR e maus tratos na infância } \\
\text { sobre o risco de DBP. }\end{array}$ & $\begin{array}{c}\text { Entre os } 1804 \text { internos } \\
\text { chineses Han do sexo } \\
\text { masculino, } 765 \text { internos que } \\
\text { tinham TPB ou transtorno de } \\
\text { personalidade anti-social } \\
\text { (ASPD) ou crime altamente } \\
\text { impulsivo ou violento foram } \\
\text { considerados internos de alto } \\
\text { risco e incluídos neste estudo. }\end{array}$ & 2020 \\
\hline
\end{tabular}

*O símbolo “ $X$ ” faz jus a falta de população no artigo encontrado.

Fonte: Os autores (2021).

O enfoque das publicações coletadas que corroboram para o objetivo do artigo destaca alterações comportamentais, de humor e neuropsicológica. Mais especificamente, no caso dessa última, alterações em estrutura e função (na região límbica e do córtex) e alterações cognitivas. Além disso, também foram encontrados possíveis preditores do desenvolvimento do transtorno em homens, assim como comorbidades.

Assim, a fim de descrever de maneira pormenorizada os dados encontrados, eles foram apresentados nos Quadros 3, 4, 5, 6, e 7, levando em consideração a organização dos artigos e suas enumerações encontradas no Quadro 1. Dito isso, cada item possui ao seu lado a numeração dos artigos correspondentes.

As alterações comportamentais (Quadro 3) mais recorrentes entre os trabalhos coletados (Quadro 1) são: Agressão (37,5\%); Comportamento Impulsivo (25\%); Comportamento autodestrutivo (16,66\%); comportamento romântico alterado $(12,5 \%)$ e hostilidade $(8,33 \%)$.

Quadro 3. Alterações comportamentais de acordo a enumeração do Quadro 1

\begin{tabular}{|c|c|c|}
\hline ITEM & ALTERAÇÕES COMPORTAMENTAIS & ARTIGOS \\
\hline 1 & Agressão & [2]; [5]; [7] [9] [14]; [15]; [17]; [20] [21] \\
\hline 2 & Comportamento Impulsivo $[3][10][12][19],[23]$ \\
\hline 3 & Comportamento autodestrutivo & [2] [14]; [18] [19] \\
\hline 4 & Comportamento romântico alterado & {$[7][17],[23]$} \\
\hline 5 & Hostilidade & {$[23]$} \\
\hline 6 & Comportamento Compulsivo & {$[2] ;$} \\
\hline 7 & Uso e abuso de substâncias & {$[2]$} \\
\hline
\end{tabular}

*O símbolo "[ ]" acompanhado de uma enumeração no eixo artigos faz menção a enumeração do artigo no Quadro 1 e a respectiva ordem apresentada.

Fonte: Os autores (2021).

Em relação às alterações de humor (Quadro 4), os artigos destacavam com maior frequência desregulação emocional $(12,5 \%)$ e a perda de interesse ou prazer nas atividades (12,5\%). Cabe aqui ressaltar que a raiva $(4,16 \%)$ também é um achado demasiadamente importante, não obstante o quantitativo tenha sido baixo. 
Quadro 4. Alterações de humor de acordo a enumeração do Quadro 1

\begin{tabular}{|c|c|c|}
\hline ITEM & ALTERAÇÕES DE HUMOR & ARTIGOS \\
\hline 1 & Desregulação Emocional & [7]; [19] [24] \\
\hline 2 & Perda de interesse ou prazer nas atividades & {$[2] ;[22] ;[23]$} \\
\hline 3 & Raiva & {$[21]$} \\
\hline 4 & Ansiedade & {[} \\
\hline
\end{tabular}

*O símbolo "[ ]" acompanhado de uma enumeração no eixo artigos faz menção a enumeração do artigo no Quadro 1 e a respectiva ordem apresentada.

Fonte: Os autores (2021).

Na observação do Quadro 5, evidenciam-se alterações neuropsicológicas subdivididas entre alterações em estrutura e função e alterações cognitivas. Dito isso, na primeira divisão, as alterações mais encontradas fazem menção a: Alterações na região da amígdala (20,83\%); alterações nas regiões do córtex $(16,66 \%)$; alterações no hipocampo (16,66\%); e alterações nos níveis de cortisol (8,33\%). Na segunda, fazem menção a alterações na memória (8,33\%) e atenção (8,33\%).

Quadro 5. Alterações de neuropsicológicas de acordo a enumeração do Quadro 1

\begin{tabular}{|c|c|c|}
\hline ITEM & ALTERAÇõES NEUROPSICOLÓGICAS & ARTIGOS \\
\hline 1 & Alterações na região da amígdala & [2] [9] [12] [15] [16] [12] [22] [16] \\
\hline 2 & Alterações nas regiões do córtex & [9] [13] [22] [16] \\
\hline 3 & Alteração no hipocampo & {$[11][20]$} \\
\hline 4 & Alterações nos níveis de cortisol & {$[12][16]$} \\
\hline 4 & Alterações na atenção & {$[16]$} \\
\hline 6 & Alterações na memória & {$[2]$} \\
\hline 7 & Baixa mentalidade & {$[2]$} \\
\hline 8 & Tempo de reação atrasados & \\
\hline
\end{tabular}

*O símbolo "[ ]" acompanhado de uma enumeração no eixo artigos faz menção a enumeração do artigo no Quadro

1 e a respectiva ordem apresentada.

Fonte: Os autores (2021).

Enfim, nos quadros 6 e 7 foi possível identificar, no caso do Quadro 6, os preditores para o desenvolvimento do TPB e no Quadro 7, as comorbidades. Dentre os principais achados referentes aos preditores, destaca-se o mau trato e abuso/violência no período da infância (16,66\%), não obstante sejam apresentados fatores genéticos também de grande importância. Já no que se refere às comorbidades, destacam-se 5 transtornos psiquiátricos, sendo que o transtorno depressivo, de ansiedade e por uso de substâncias são os que mais aparecem. 
Quadro 6. Preditores para o desenvolvimento do TPB dispostos de acordo a enumeração do Quadro 1

\begin{tabular}{|c|c|c|}
\hline ITEM & PREDITORES & ARTIGOS \\
\hline $\mathbf{1}$ & Mau trato e Abuso/Violência no período da infância & [2] [4] [8] [9] \\
\hline 2 & Vulnerabilidade genética & {$[22]$} \\
\hline 3 & Interações do gene receptor da ocitocina (OXTR rs53576) & {$[24]$} \\
\hline 4 & Variação genética nos genes do eixo hipotálamo-pituitária-adrenal (HPA) & [1] \\
\hline
\end{tabular}

*O símbolo "[ ]" acompanhado de uma enumeração no eixo artigos faz menção a enumeração do artigo no Quadro

1 e a respectiva ordem apresentada.

Fonte: Os autores (2021).

Quadro 7. Comorbidades organizadas de acordo a enumeração do Quadro 1

\begin{tabular}{|c|c|c|}
\hline ITEM & COMORBIDADES & ARTIGOS \\
\hline 1 & Transtorno depressivo & {$[3][20]$} \\
\hline 2 & Transtorno de ansiedade & {$[3][21]$} \\
\hline 3 & Transtorno por uso de substâncias & {$[22]$} \\
\hline 4 & Transtorno de estresse pós traumático & {$[20]$} \\
\hline 5 & Transtorno Bipolar & {$[3]$} \\
\hline
\end{tabular}

*O símbolo "[ ]" acompanhado de uma enumeração no eixo artigos faz menção a enumeração do artigo no Quadro 1 e a respectiva ordem apresentada.

Fonte: Os autores (2021).

\section{Discussão}

O transtorno de personalidade borderline atinge uma média de 1,6\% da população geral. De modo geral, a literatura especializada o caracteriza pela instabilidade na regulação do afeto, controle de impulso, relações interpessoais e autopercepção (APA, 2014). No entanto, como já mencionado, essas definições genéricas, por vez, direcionam-se a uma amostra populacional de mulheres; logo, trazem enquanto questão quais as diferenças e semelhanças que podem vir a ser encontradas quando realizamos um comparativo entre homens e mulheres com borderline. Afinal, melhor dizendo, quais as características e fatores envolvem o transtorno borderline em homens? Posto isso, entendendo que o borderline é um transtorno clinicamente heterogêneo e envolve diversas nuances, a importância de reconhecer as suas especificidades, características e alterações em homens se direcionam para um olhar mais detalhado sobre o que envolve a patologia.

O transtorno de personalidade borderline compreende uma amplitude de comportamentos que envolvem o prejuízo a si mesmo e aos outros de maneira significativa. No homem, a agressão (ou agressividade) aparece em um nível exacerbado e é destaque ao falar dessa patologia nessa gama de indivíduos (Bayes \& Parker, 2017).

Em um estudo com uma amostra de 33 pacientes do sexo feminino e 23 do sexo masculino com TPB, e 30 mulheres e 26 homens sem TPB, os resultados indicaram que pacientes do sexo masculino se revelaram mais propícios a serem agressivos (Herpertz et al., 2017). Da mesma maneira, Lu et al. (2018), ao objetivar examinar as diferenças comportamentais e na saúde mental de jovens adultos com sintomas do borderline, investigou, através da versão taiwanesa da Lista de sintomas limítrofes (BSL-23), 500 estudantes universitários, encontrando em seus resultados que homens com borderline apresentam uma maior taxa significativa de agressividade. De acordo com Falcus \& Johnson (2017), a vergonha internalizada e a regulação inadequada são fatores-chaves que levam à agressão e à violência por parte de homens com TPB. 
Navarro-Gómez et al. (2017) sugerem que os comportamentos agressivos dos homens são comumente apresentados em seus relacionamentos afetivos. Isso se dá, sobretudo, à maneira como se relacionam intensamente e possuem um alto grau de frustração, resultando então, em relacionamentos altamente instáveis e com um número grande de separação. Além disso, Bayes \& Parker (2017) destacam que o aumento de agressões a parceiros íntimos e violência em geral é gerenciado de acordo com a gravidade dos casos, não obstante isso destaque a presença da agressão nos mais diferentes níveis do transtorno. Ainda segundo o autor, os homens que realizavam a violência doméstica foram avaliados com taxas mais altas de TPB em contraste com homens não abusivos.

Esses achados acerca da agressão em homens com TPB corroboram e se associam com aqueles que apontam altos níveis de raiva e uma evidente desregulação emocional, fatos estes associados. Os grandes índices de agressão, por vez, podem então serem respaldados na dificuldade que os pacientes com TPB encontram para sua própria regulação emocional, que por sua vez resulta nos níveis elevados de raiva, tal como sugere Bayes \& Parker (2017), além de Zhang et al. (2020) e Steele et al. (2020).

Kaess et al. (2017) apontam que os níveis elevados de raiva e, consequentemente, comportamentos agressivos são geridos pelos níveis alterados de cortisol em homens com TPB. Segundo Thomas et al (2019), em um de seus resultados de uma revisão de literatura realizada, a hipótese de hormônio duplo postula que o cortisol basal e a testosterona interagem para influenciar os sistemas comportamentais implicados em traços como empatia e agressão.

Enfim, em um único estudo, em um comparativo entre mulheres e homens, foi mencionado que indivíduos do sexo feminino com TPB apresentavam maiores níveis de agressividade do que o homem, mesmo que isso contrariasse a literatura vigente (Van den Brink, 2018).

Homens também podem apresentar comportamento Impulsivo (Yalch, Levendosky \& Alytia, 2019). Segundo (Bayes \& Parker, 2017), homens apresentam níveis elevados de impulsividade. Holthausen \& Habel (2018), ao realizarem um estudo de revisão objetivando apresentar as diferenças sexuais em alguns transtornos de personalidade, também obtiveram como resultado que, a partir de uma investigação psicométrica utilizando a teoria de resposta ao item, diferente das mulheres, homens eram mais propensos a endossar a impulsividade nos diferentes contextos da vida.

De acordo com Steele et al. (2019), altos níveis de impulsividade no homem podem levar à automutilação e suicídio. Esses altos níveis de impulsividade são considerados como responsáveis por dificuldades na formação e manutenção de relacionamentos interpessoais, diz o autor. Aparentemente, essa impulsividade do homem está ligada a alterações no córtex orbitofrontal, região essa envolvida em funções executivas que regulam a implementação da decisão e comportamentos impulsivos (Kaplan et al., 2020).

Além de comportamentos impulsivos e agressivos, homens com TPB tendem a apresentar comportamentos autodestrutivos em uma grande proporção, embora no caso desse comportamento não apresentem diferenças significativas às mulheres (ㄴu et al., 2018). Mas, ainda sim, com base no estudo de Bayes \& Parker (2017), homens apresentam graus elevados de comportamentos autodestrutivos como, em especial, tentativas de suicídio e automutilação.

Sher et al. (2019), ao examinar as diferenças de gênero e semelhanças na agressão, impulsividade, comportamento suicida e comorbidade psiquiátrica em homens ( $n=145)$ e mulheres $(n=203)$ com TPB em comparação com controles saudáveis homens $(n=81)$ e mulheres $(n=82)$, encontrou em seus resultados, primeiramente, que os pacientes com TPB apresentavam alto risco de tentativas de suicídio e suicídio consumado e, no caso dos homens, demonstravam poder ter maior risco de morrer por suicídio em comparação com mulheres com TPB.

Ademais, cabe mencionar mais uma vez que, como citado anteriormente, esses comportamentos autodestrutivos podem ter relação em algum grau com os níveis elevados de impulsividade (Steele et al., 2019).

Além da identificação de questões comportamentais e emocionais que melhor caracterizam o borderline em homens, algumas alterações neuropsicológicas também são presentes e contribuem para esses achados, entendendo que alterações neuropsicológicas, aqui, são a nível cognitivo e alterações em estrutura e função. 
Segundo Nascimento, Cerqueira \& Araujo Filho (2021) e Bayes \& Parker (2017), homens apresentam alterações no sistema límbico, sobretudo na região da amígdala e do hipocampo. Nascimento, Cerqueira \& Araujo Filho (2021), em um estudo de revisão que objetivou apresentar evidências científicas e sistematizar as principais compreensões da literatura científica acerca das características e alterações neuropsicológicas presentes no TPB, os autores encontraram que pacientes com TPB apresentam alterações significativas na amígdala, sobretudo, no caso dos homens, a ativação da amígdala esquerda. Da mesma maneira, Bayes \& Parker (2017), em outra revisão, concluem que homens apresentam ativação aprimorada da amígdala esquerda na presença de imagens de alta saliência, dado esse também corroborado com a pesquisa realizada por Herpertz et al. (2017), em que pacientes do sexo masculino com TPB apresentavam maior ativação na amígdala esquerda, em especial nos momentos de indução de raiva e agressão, no qual a amígdala desempenha um papel central no processamento de ameaças. Herpertz et al. (2017) também encontraram um efeito modulador negativo do traço da raiva no acoplamento entre a amígdala esquerda por um lado e um grande agrupamento no córtex ventrolateral prefrontal direito e no córtex orbitofrontal.

Ainda sobre a amígdala, em um estudo feito por Mancke et al. (2018) com amostra mista de 60 pacientes adultos com TPB sem uso de medicação corrente e 51 voluntários saudáveis, encontrou-se uma tendência para a associação entre o volume da amígdala direita e agressividade em pacientes com TPB do sexo masculino. Os resultados também revelaram dois grupos da amígdala esquerda (amígdala superficial e amígdala laterobasal) que estão eminentemente associados à agressividade em pacientes do sexo masculino com borderline.

No que se refere ao hipocampo, Herpertz et al. (2017) e Nascimento et al. (2021) destacam alterações nessa região em homens, não obstante também apareça em mulheres. Especificamente no caso do homem, no estudo de revisão realizado por Winsper et al. (2016) no qual se objetivava apresentar e avaliar as evidências sobre a neurobiologia do TPB na infância e adolescência em contraste com a literatura adulta, foi encontrada a presença de assimetria hipocampal direita atípica associada a baixa afiliação. Do mesmo modo, Khoury et al. (2019), em seus resultados, descreve que algumas características comuns no TPB em homens, como incidência de suicídio e autolesão, foram associadas ao aumento do volume do hipocampo esquerdo

Já em relação às alterações na região do córtex, Herpertz et al. (2017) ressalta que homens apresentam uma ativação significativamente maior no córtex pré-frontal dorsolateral direito. $E$, referindo-se à estrutura, Winsper et al. (2016) aponta a redução no volume do córtex orbitofrontal por parte de pacientes com TPB em comparação com grupos de controle.

Enfim, alterações na atenção e memória também se mostraram presentes (Nascimento et al., 2021). De acordo com Kaplan et al. (2020), em seu estudo, os grupos com TPB apresentavam menor atenção sustentada, reconhecimento de emoção facial e funções de memória verbal em comparação com o grupo de saudáveis. Além disso, de acordo com o autor, essas alterações cognitivas podem vir a ter alguma associação com a questão do suicídio.

Acerca dos fatores envolvidos no desenvolvimento do borderline, tem-se que os principais fatores envolvem maus tratos na infância, não obstante apareçam alguns fatores genéticos envolvidos. Nos resultados do estudo feito por Ferreira et al. (2018), é descrita uma tendência significativa entre abuso sexual na infância e o desenvolvimento do TPB apenas em homens. Godbout et al. (2019) traz que os maus tratos paternos a crianças do sexo masculino é um significativo preditor do desenvolvimento do TPB; melhor dizendo, há uma associação direta entre maus tratos paternos e o desenvolvimento.

Por fim, geneticamente falando, Amad et al. (2019) encontraram a hipótese de que a variação genética nos genes do eixo hipotálamo-pituitária-adrenal contribui para a suscetibilidade ao TPB. Além disso, Zhang et al. (2020) relevaram uma interação entre o OXTR rs53576 e o abuso sexual. Conforme explicita o autor, em casos com níveis mais baixos de abuso sexual, a probabilidade do desenvolvimento do TPB foram menores entre aqueles com genótipo GG, enquanto que em níveis mais elevados de abuso sexual, as probabilidades para o desenvolvimento foram menores entre aqueles com alelo A. Ainda, quando os indivíduos tinham níveis de abuso físico mais baixos, aqueles que carregavam o genótipo GG tinham um risco menor de desenvolverem o borderline do que aqueles que carregavam o alelo $A$, enquanto que os indivíduos que possuíam escores de abuso físico 
mais altos e carregavam o genótipo GG apresentavam maiores chances de desenvolverem o TPB do que aqueles que carregavam o alelo $\mathrm{A}$.

\section{Conclusão}

Em vista da amplitude etiológica e dos modos de compreensão e manifestação do Transtorno de Personalidade Borderline (TPB) em homens, buscou-se, através da realização do presente estudo, sistematizar as principais características e alterações comportamentais, de humor e neuropsicológicas associadas à presença do transtorno. De forma preliminar, foi possível concluir que existem algumas dessas alterações que são mais prevalentes no gênero masculino.

Entre as principais alterações comportamentais, concluímos que homens apresentam mais: agressão, comportamento impulsivo, comportamento autodestrutivo, comportamento romântico alterado e hostilidade. Quanto aos achados sobre a alteração de humor, temos: desregulação emocional e a perda de interesse ou prazer nas atividades. Já a respeito das alterações neuropsicológicas: alterações na região da amígdala, alterações nas regiões do córtex, no hipocampo e nos níveis de cortisol, bem como na atenção e memória.

Ademais, também foram encontrados possíveis fatores referentes ao desenvolvimento do TPB, destacando: o mau trato e abuso/violência no período da infância e fatores genéticos. Além disso, já no que se refere às comorbidades, destacam-se alguns transtornos psiquiátricos, em especial, no homem, o transtorno depressivo, de ansiedade e por uso de substâncias.

Assim, através do mapeamento sobre os achados a respeito do transtorno de personalidade borderline em homens, tornou-se possível organizar em um único local os principais achados que, de alguma maneira, propuseram-se a elucidar e ampliar o debate referente à patologia do borderline, facilitando também a busca dessas informações na literatura brasileira e, principalmente, contribuindo para essa discussão.
Por fim, a limitação desse estudo encontra-se no fato das produções, por vez, apresentarem as características, alterações e fatores do transtorno bordeline em homens sem contrastarem com a população de mulheres. Além disso, os estudos encontrados nem sempre fizeram correlação entre um fator comportamental, um emocional e um neuropsicológico. Portanto, em alguns momentos, esse estudo sugeriu algumas correspondências entre os achados mencionados. Sendo assim, tornam-se necessárias maiores investigações em busca de melhores evidências científicas. Logo, sugerimos a importância de pesquisar e ampliar a discussão acerca do Transtorno de Personalidade Borderline (TPB) em homens na literatura brasileira, em especial devido à escassez dessa discussão na literatura e à falta de dados significativos acerca das características, alterações e fatores que envolvem o TPB em uma amostra populacional brasileira, configurando-se, então, novos caminhos para pesquisas futuras.

\section{Contribuições dos autores}

Nascimento RB, Cerqueira G de L, Araújo Filho ES, Carneiro DG realizaram a pesquisa integrativa, extração e discussão de dados, assim como a redação do artigo.

\section{Conflitos de interesses}

Nenhum conflito financeiro, legal ou político envolvendo terceiros (governo, empresas e fundações privadas, etc.) foi declarado para nenhum aspecto do trabalho submetido (incluindo, mas não se limitando a subvenções e financiamentos, participação em conselho consultivo, desenho de estudo, preparação de manuscrito, análise estatística, etc.).

\section{Referências}

Amad, A., Ramoz, N., Peyre, H., Thomas, P., \& Gorwood, P. (2019). FKBP5 gene variants and borderline personality disorder [Variantes do gene KBP5 e distúrbio de personalidade limítrofe]. Journal of affective disorders, 248, 26-28. https:// doi.org/10.1016/j.jad.2019.01.025

American Psychiatric Association. (2014). Manual diagnóstico e estatístico de transtornos mentais: DSM-5 (5a ed.). Artmed. 
Bayes, A., \& Parker, G. (2017). Borderline personality disorder in men: A literature review and illustrative case vignettes [Transtorno de personalidade Borderline e nos homens: Uma revisão bibliográfica e vinhetas de casos ilustrativos]. Psychiatry research, 257, 197-202. https://doi.org/10.1016/j. psychres.2017.07.047

Chapman, J., Jamil, R. T., \& Fleisher, C. (2021). Borderline Personality Disorder. In StatPearls. StatPearls Publishing. https://www.ncbi.nlm.nih.gov/books/NBK430883/

Chen, S. F., Lin, C. L., Wang, L. Y., Wang, J. H., Hsu, C. Y., \& Shen, Y. C. (2019). Borderline personality disorder is associated with an increased risk of sexually transmitted infections: A nationwide population-based cohort study in Taiwan [O distúrbio de personalidade Borderline está associado a um risco aumentado de infecções sexualmente transmissíveis: Um estudo de coorte a nível nacional com base na população de Taiwan]. Sexually transmitted infections, 95(7), 529-533. https://doi.org/10.1136/ sextrans-2018-053812

Dalgalarrondo, P. (2019). Psicopatologia e semiologia dos transtornos mentais ( $3^{\mathrm{a}}$ ed). Artmed.

Ferreira, L. F. A., Pereira, F. H. Q., Benevides, A. N., \& Melo, M. C. A. (2018). Borderline personality disorder and sexual abuse: A systematic review [Transtorno de personalidade Borderline e abuso sexual: Uma revisão sistemática]. Psychiatry research, 262, 70-77. https://doi.org/10.1016/j. psychres.2018.01.043

Ellison, W. D., Rosenstein, L. K., Morgan, T. A., \& Zimmerman, M. (2018). Community and Clinical Epidemiology of Borderline Personality Disorder [Epidemiologia Comunitária e Clínica da Perturbação da Personalidade Borderline]. The Psychiatric clinics of North America, 41(4), 561-573. https://doi.org/10.1016/j.psc.2018.07.008

Falcus, C., \& Johnson, D. (2018). The Violent Accounts of Men Diagnosed With Comorbid Antisocial and Borderline Personality Disorders [Os Relatos Violentos de Homens Diagnosticados com Transtornos de Personalidade Antissociais e Borderline Combinados]. International journal of offender therapy and comparative criminology, 62(9), 2817-2830. https://doi. org/10.1177/0306624X17735254

Foxhall, M., Hamilton-Giachritsis, C., \& Button, K. (2019). The link between rejection sensitivity and borderline personality disorder: A systematic review and meta-analysis [A ligação entre a sensibilidade de rejeição e o distúrbio de personalidade borderline: Uma revisão sistemática e uma meta-análise]. The British journal of clinical psychology, 58(3), 289-326. https://doi.org/10.1111/bjc.12216
Frías, Á., Palma, C., Farriols, N., \& González, L. (2016). Sexualityrelated issues in borderline personality disorder: $\mathrm{A}$ comprehensive review [Questões relacionadas com a sexualidade em distúrbios de personalidade borderline: Uma revisão abrangente]. Personality and mental health, 10(3), 216-231. https://doi.org/10.1002/pmh.1330

Godbout, N., Daspe, M. È., Runtz, M., Cyr, G., \& Briere, J. (2019). Childhood maltreatment, attachment, and borderline personality-related symptoms: Gender-specific structural equation models [Maus-tratos infantis, apego, e sintomas relacionados com a personalidade: Modelos de equações estruturais específicas de género]. Psychological trauma: theory, research, practice and policy, 11(1), 90-98. https:// doi.org/10.1037/tra0000403

Herpertz, S. C., Nagy, K., Ueltzhöffer, K., Schmitt, R., Mancke, F., Schmahl, C., \& Bertsch, K. (2017). Brain Mechanisms Underlying Reactive Aggression in Borderline Personality Disorder-Sex Matters [Mecanismos Cerebral Subjacentes à Agressão Reativa na Personalidade Borderline - Questões de Transtorno Sexual]. Biological psychiatry, 82(4), 257-266. https://doi.org/10.1016/j.biopsych.2017.02.1175

Holthausen, B. S., \& Habel, U. (2018). Sex Differences in Personality Disorders [Diferenças sexuais em Distúrbios de Personalidade]. Current psychiatry reports, 20(12), 107. https://doi.org/10.1007/s11920-018-0975-y

Kaess, M., Whittle, S., Simmons, J. G., Jovev, M., Allen, N. B., \& Chanen, A. M. (2017). The Interaction of Childhood Maltreatment, Sex, and Borderline Personality Features in the Prediction of the Cortisol Awakening Response in Adolescents [A interacção de maus-tratos infantis, sexo e características de personalidade borderline na previsão da resposta do despertar do Cortisol nos Adolescentes]. Psychopathology, 50(3), 188-194. https:// doi.org/10.1159/000456549

Kaplan, B., Gulec, M. Y., Gica, S., \& Gulec, H. (2020). The association between neurocognitive functioning and clinical features of borderline personality disorder [A associação entre o funcionamento neurocognitivo e as características clínicas do distúrbio de personalidade borderline]. Brazilian Journal of Psychiatry, 42(5), 503-509. Epub April 17, 2020. https://dx.doi.org/10.1590/1516-4446-2019-0752

Khoury, J. E., Pechtel, P., Andersen, C. M., Teicher, M. H., \& LyonsRuth, K. (2019). Relations among maternal withdrawal in infancy, borderline features, suicidality/self-injury, and adult hippocampal volume: A 30-year longitudinal study [Relações entre a abstinência materna na infância, características borderline, suicídio/auto-agressão, e volume hipocampal adulto: Um estudo longitudinal de 30 anos]. Behavioural brain research, 374, 112139. https://doi. org/10.1016/j.bbr.2019.112139 
Lu, W. H., Wang, P. W., Ko, C. H., Hsiao, R. C., Liu, T. L., \& Yen, C. F. (2018). Differences in mental health among young adults with borderline personality symptoms of various severities [Diferenças na saúde mental entre adultos jovens com sintomas de personalidade borderline com vários graus de severidade]. Journal of the Formosan Medical Association = Taiwan yi zhi, 117(4), 332-338. https://doi.org/10.1016/j. jfma.2017.04.020

Mancke, F., Herpertz, S. C., Hirjak, D., Knies, R., \& Bertsch, K. (2018). Amygdala structure and aggressiveness in borderline personality disorder [Estrutura da Amygdala e agressividade no transtorno de personalidade borderline]. European archives of psychiatry and clinical neuroscience, 268(4), 417-427. https://doi.org/10.1007/s00406-016-0747-9

Nascimento, R. B., Cerqueira, G. L., \& Araujo Filho, E. S. (2021). Características e alterações neuropsicológicas no Transtorno de Personalidade Borderline: uma revisão da literatura. Revista Ibero-Americana de Humanidades, Ciências e Educação, 7(4), 322-347. https://doi. org/10.51891/rease.v7i4.968

Navarro-Gómez, S., Frías, Á., \& Palma, C. (2017). Romantic Relationships of People with Borderline Personality: A Narrative Review [Relacionamentos Românticos de Pessoas com Personalidade Borderline: Uma Revisão Narrativa]. Psychopathology, 50(3), 175-187. https://doi. org/10.1159/000474950

Sher, L., Rutter, S. B., New, A. S., Siever, L. J., \& Hazlett, E. A. (2019). Gender differences and similarities in aggression, suicidal behaviour, and psychiatric comorbidity in borderline personality disorder [Diferenças e semelhanças de género em agressão, comportamento suicida e comorbidade psiquiátrica em transtorno de personalidade borderline]. Acta psychiatrica Scandinavica, 139(2), 145-153. https://doi. org/10.1111/acps.12981

Souza, M. T., Silva, M. D., \& Carvalho, R. (2010). Revisão integrativa: o que é e como fazer [Integrative review: what it is and how to do it]. Einstein (São Paulo), 8(1), 102-106. https://doi. org/10.1590/s1679-45082010rw1134

Steele, K. R., Townsend, M. L., \& Grenyer, B. (2019). Parenting and personality disorder: An overview and meta-synthesis of systematic reviews [Paternidade e transtorno de personalidade: Uma visão geral e meta-síntese de revisões sistemáticas]. PloS one, 14(10), e0223038. https://doi. org/10.1371/journal.pone.0223038
Thomas, N., Gurvich, C., Hudaib, A. R., Gavrilidis, E., \& Kulkarni, J. (2019). Systematic review and meta-analysis of basal cortisol levels in Borderline Personality Disorder compared to non-psychiatric controls [Revisão sistemática e meta-análise dos níveis de cortisol basal na Perturbação da Personalidade Borderline em comparação com os controles não psiquiátricos]. Psychoneuroendocrinology, 102, 149-153. https://doi. org/10.1016/j.psyneuen.2018.12.009

Van den Brink, C., Harte, J. M., \& Denzel, A. D. (2018). Men and women with borderline personality disorder resident in Dutch special psychiatric units in prisons: A descriptive and comparative study [Homens e mulheres com transtorno de personalidade borderline residentes em unidades psiquiátricas especiais nas prisões holandesas: Um estudo descritivo e comparative]. Criminal behaviour and mental health: CBMH, 28(4), 324-334. https://doi. org/10.1002/cbm.2084

Winsper, C., Marwaha, S., Lereya, S. T., Thompson, A., Eyden, J., \& Singh, S. P. (2016). A systematic review of the neurobiological underpinnings of borderline personality disorder (BPD) in childhood and adolescence [Uma revisão sistemática dos fundamentos neurobiológicos da transtorno de personalidade borderline (BPD) na infância e adolescência]. Reviews in the neurosciences, 27(8), 827-847. https://doi.org/10.1515/revneuro-2016-0026

Yalch, M. M., \& Levendosky, A. A. (2019). Influence of betrayal trauma on borderline personality disorder traits [Influência do trauma de traição nos traços de personalidade borderline]. Journal of trauma \& dissociation: the official journal of the International Society for the Study of Dissociation (ISSD), 20(4), 392-401. https://doi.org/10.1080/ 15299732.2019.1572042

Zhang, M., Liu, N., \& Chen, H. (2020). Oxytocin receptor gene, childhood maltreatment and borderline personality disorder features among male inmates in China [O gene receptor da oxitocina, maus-tratos infantis e distúrbios de personalidade borderline entre os reclusos masculinos na China]. BMC Psychiatry, 20, 332. https://doi.org/10.1186/ s12888-020-02710-0 